\title{
The Impact of Adaptive Learning in Entrepreneurial Behavior for College Students
}

\author{
Dan Yang* \\ School of Graduate Studies, Lingnan University, Tuen Mun, Hong Kong SAR, China
}

Entrepreneurship of college students has always been a hot topic in families, schools and society. Massive studies aim to explore entrepreneurial behavior. However, under the condition of the $10 \%$ success rate of student entrepreneurship, the adverse impact of COVID-19 and the changed circumstance of domestic entrepreneurship, this exploration aims to study the factors that influence college students' entrepreneurial behavior choices under the epidemic. First, through the retrieval of relevant literature and theoretical study, the variable factors that affect behavior choices are sorted and summarized. It is assumed that the factors that affect behavior choices are entrepreneurial motivation, entrepreneurial ability, willingness to behave, and entrepreneurial environment. Second, a questionnaire is designed to investigate the

OPEN ACCESS

Edited by: Chin-Feng Lai, National Cheng Kung University, Taiwan

Reviewed by: Teresa Pozo-Rico,

University of Alicante, Spain Sikandar Ali Qalati, Jiangsu University, China Nor Hafiza Othman, Universiti Malaysia Kelantan, Malaysia

*Correspondence:

Dan Yang

blcu13yd@163.com

Specialty section: This article was submitted to Educational Psychology, a section of the journal

Frontiers in Psychology

Received: 18 October 2021 Accepted: 24 December 2021

Published: 22 February 2022

Citation:

Yang D (2022) The Impact of Adaptive Learning

in Entrepreneurial Behavior for College Students. Front. Psychol. 12:797459. doi: 10.3389/fpsyg.2021.797459 choice of entrepreneurial behavior for students who are starting a business or going to start a business. The standard effect values of the survey results are calculated by using structural equation modeling (SEM). The results reveal that the effect values of the nine hypothetical results are all in line with the prediction, which prove a positive impact of the four variable factors on the choice of entrepreneurial behavior. The experimental parameters set are as follows. The standardized effect value of Hypothesis 1 (entrepreneurial motivation has a positive impact on entrepreneurial behavior choice) is 0.216; that of Hypothesis 2 (entrepreneurial ability has a positive impact on the choice of entrepreneurial behavior) is 0.221 ; that of Hypothesis 3 (willingness to behave has a positive impact on entrepreneurial behavior choice) is 0.284 ; that of Hypothesis 4 (entrepreneurial environment has a positive impact on the choice of entrepreneurial behavior) is 0.329; that of Hypothesis 5 (entrepreneurial motivation has a positive impact on entrepreneurial intention) is 0.247 ; that of Hypothesis 6 (entrepreneurial ability has a positive impact on willingness to behave) is 0.339; that of Hypothesis 7 (entrepreneurial ability has a positive impact on entrepreneurial motivation) is 0.357 ; that of Hypothesis 8 (entrepreneurial environment has a positive impact on willingness to behave) is 0.336; that of Hypothesis 9 (entrepreneurial environment has a positive impact on entrepreneurial motivation) is 0.485 . Besides, the entrepreneurial environment has the greatest impact on behavior choice. Therefore, it is believed that the government, society, schools need to strengthen the correct guidance of entrepreneurial students and create a good entrepreneurial environment to cope with economic changes under the epidemic.

Keywords: college students' entrepreneurship, epidemic era, structural equation modeling, entrepreneurial behavior choice, entrepreneurial ability 


\section{INTRODUCTION}

Since the 18th National Congress of the Communist Party of China, the state has encouraged and supported college students to start their own businesses. College students from all over the country have joined the entrepreneurial trend, but the result is not optimistic (Wenfeng, 2020). As the COVID-19 swept across the cities of China at the end of 2019, the central government has promulgated strong prevention and control policies one after another, and the epidemic was finally overcome with the efforts of whole nation. However, many small and medium-sized enterprises have faced bankruptcy due to the 4-month shutdown in China, the current situation of the epidemic abroad, and the impact of uncertain factors of world trade on the economic system (Wang and $\mathrm{Hu}, 2021$ ), so that the immature college students are faced with many risks and fall into a dilemma.

Nowadays, there are not enough jobs to satisfy everyone, so the original intention of college students to start a business is to alleviate the employment pressure. Yong et al. (2020) analyzed the current situation, hotspots and frontiers of the employment pressure research of college students. The result suggested that college students' employment pressure will be affected by social support, mental health education and coping methods (Yong et al., 2020). During the epidemic period, how to promote college students' entrepreneurship is an issue that the state needs to pay more attention to. Wang et al. (2020) believed that exploratory and developmental learning will play a key role in enterprise growth performance. Therefore, it is necessary to improve the innovation of college students' entrepreneurship. Colleges need to guide students' entrepreneurship according to the situation of students. Wu et al. (2017) mentioned in the research that educators and policy makers should integrate the views of function, personality and behavior into the acceptance of entrepreneurship, so as to affect a country's economic development. Besides, in the process of entrepreneurship, students' personal psychological quality will also play a key role in entrepreneurship. Zheng et al. (2019) found that narcissism will have a negative impact on entrepreneurship. Finally, Song and Wu (2019) found that good social style and trust between partners will also have an impact on entrepreneurship. However, due to the outbreak of the epidemic, students are facing great pressure to start a business. Although entrepreneurial enthusiasm is high, the success rate is always no more than $10 \%$.

In recent years, the research mainly focuses on the entrepreneurial behavior of college students. There are more studies on entrepreneurial models and entrepreneurial projects, but few on the factors affecting entrepreneurship. After the outbreak of the epidemic, it is necessary to analyze a series of factors affecting students' entrepreneurial behavior. Therefore, this exploration aims to study the influencing factors of entrepreneurial environment on college students' entrepreneurship after the epidemic. First, relevant literature and analyses about the influencing factors of college students' entrepreneurship are collected. Then, a questionnaire on the entrepreneurial environment and entrepreneurial ability of college students who have started or will start a business is made. Finally, the data analysis software SPSS26.0 (statistical product and service solutions) and the analysis algorithm structural equation modeling (SEM) are used to test the reliability and validity of the survey results to verify the correlation between variables. The innovation is to analyze the behavioral influencing factors of entrepreneurs' entrepreneurial behavior.

\section{LITERATURE REVIEW}

Many studies have confirmed the impact of the epidemic on entrepreneurs' willingness. Ting et al. (2021) conducted a multi factor analysis on the opportunities for the sustainable development of professional sports enterprises and events from the perspective of public awareness, attitude and behavior, as well as the physical and mental health of spectators of professional events in Taiwan. It aimed to maintain the normal operation of professional sports companies and events under the COVID-19, and create a sustainable development environment for them (Ting et al., 2021). Cao and Wang (2020) found that since the COVID-19 pandemic, China's higher vocational college students have encountered great problems in finding jobs. They believed that efforts should be made to improve the employment environment to improve students' attitude, self-quality and personal entrepreneurial interest. In addition, government policies and family support were considered to assess the impact of external support on students' decisions. The results show that students' attitude, self-quality, and personal interest will affect their entrepreneurial intention. The impact of family support is greater than that of government policy. Government policies have no significant impact on students' entrepreneurial intention (Cao and Wang, 2020). The above two studies theoretically show that the epidemic has a significant impact on entrepreneurial intention. Given the significant impact of new enterprises on the global economy, Murnieks et al. (2020) understood the motivation of entrepreneurs, which had practical and theoretical importance. It could make people understand how motivation drives the start-up, growth and exit of enterprises. The existing literature was sorted out and reviewed based on the entrepreneurial motivation of each stage of the new entrepreneurial process. Therefore, the research status of entrepreneurial motivation and the road map of its rule network were formulated, and suggestions were provided to guide future research, so as to expand people's understanding of motivation in the field of entrepreneurship and traditional organizational environment (Murnieks et al., 2020). Allmendinger and Berger (2020) tried to understand when the founders of new enterprises are willing to participate in this asymmetric partnership by considering the characteristics of entrepreneurial decision-makers and the perceived attributes of larger competitors. The research shows that entrepreneurs' selfefficacy reduces the positive impact of cooperation intention and concise contract design. The results have an impact on the selfconcept and design of innovation and partner management of large companies, as well as entrepreneurs who regard asymmetric partnerships as growth opportunities (Allmendinger and Berger, 2020). Through experiments, these experts proved that individual entrepreneurial opportunities are affected by entrepreneurial 
environment and entrepreneurial intention, and the impact of entrepreneurial environment is the most significant. Boahemaah et al. (2020) studied the impact of entrepreneurship intention education on college students through personal factors (attitude toward behavior, entrepreneurial motivation, entrepreneurial resources and perceived behavior control). The results reveal that individual factors and entrepreneurship education have a direct positive impact on entrepreneurship intention (Boahemaah et al., 2020). Caliendo et al. (2020) analyzed the impact of personal level (human capital and personality) and the impact of business-related characteristics on these two indicators and their relative importance. It shows that the results are heterogeneous between groups. In particular, the previously founders have no difference in survival opportunities, but they are more likely to lack a high psychological commitment to entrepreneurship (Caliendo et al., 2020). Through the experiment, the specific influencing factors of entrepreneurial motivation were predicted, and the experimental results were verified, which further shows that the entrepreneurial environment exerts a great impact on entrepreneurial motivation. Therefore, this exploration will take entrepreneurial environment as the main factor to explore the influencing factors of COVID-19's entrepreneurial motivation.

\section{MATERIALS AND METHODS}

\section{College Students' Entrepreneurship}

Due to the transformation of the market economy and the increase of employment pressure, entrepreneurship, as a free way of career choice, has been favored by young people (Zhang, 2020). College students' entrepreneurship is the social behavior of college students or graduates to create independent enterprises. However, it has both advantages and disadvantages. To provide support for college students' entrepreneurship, many scholars believe that students must improve their comprehensive ability, schools should pay attention to the cultivation of entrepreneurial ability, and society must focus more on students' entrepreneurship.

Entrepreneurial behavior comes from the west, not only the operation of large-scale organizations, but also the groups preparing to set up new enterprises. The concept of planned behavior theory is a result of individual thinking. It can help people understand how individuals change their behavior, so as to explain and predict individual behavior more appropriately. Planned behavior is a perfect concept of social psychology and has been applied in the world (Schmidt and Stenger, 2021). Figure 1 displays its theoretical structure.

Ternary interaction theory is a theory that describes the interaction among the individual, behavior and environment. The three elements interact and act as cause and effect, which determine the occurrence and realization of various behaviors together. The individual elements in the ternary interaction theory can trigger individuals to perceive and understand other internal characteristics, including personal IQ, personality, confidence, attitude, and view of things (Feng, 2020). It also includes physiological characteristics, race, temperament and heredity. The environment is unstable and generally affects
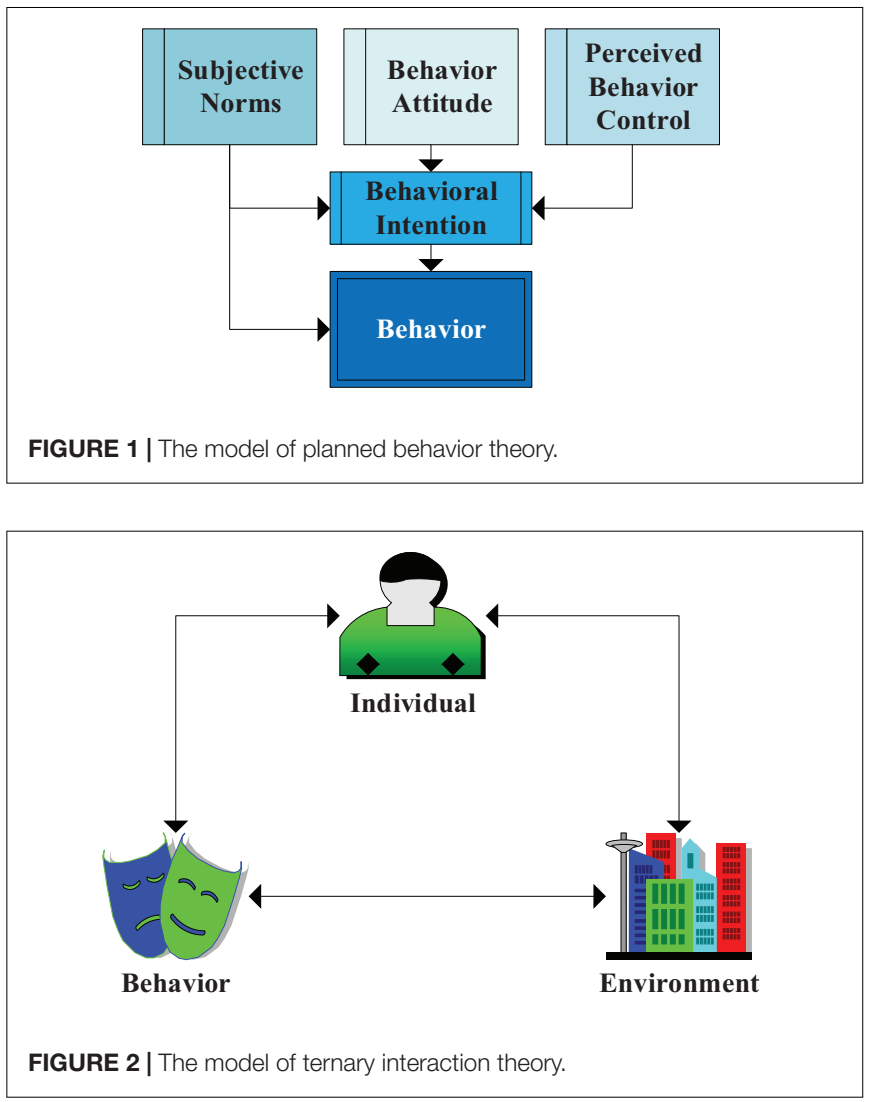

people through behavior. The three coexist and promote together. Figure 2 shows the structure.

In recent years, the research on the choice of college students' entrepreneurial behavior has increased. The research has found that most college students choose the tertiary industry, so few will get official help and venture capital. There are great differences in the industry, enterprise scale and capital source of college students' entrepreneurship choice. Some scholars believe that the choice of entrepreneurship has certain rules, among which the most influential factors are funds, prospects, environment and competitiveness. However, the others believe that personal personality is the main influencing factor (Vodà and Florea, 2019), followed by family, professional restrictions and gender (Hutasuhut, 2018; Wang et al., 2018). Some studies show that entrepreneurs have summarized four influencing factors from the entrepreneurial process. Figure 3 displays the four influencing factors.

\section{Hypothesis of Influencing Factors of College Students' Entrepreneurship Choice Behavior}

Based on the factors affecting entrepreneurial choice behavior studied by previous scholars, the impact of social changes on entrepreneurial choice behavior after the epidemic is analyzed, and the variable factors according to the concept of planned behavior and ternary interaction theory are assumed. Through literature review and previous research results, it is considered 


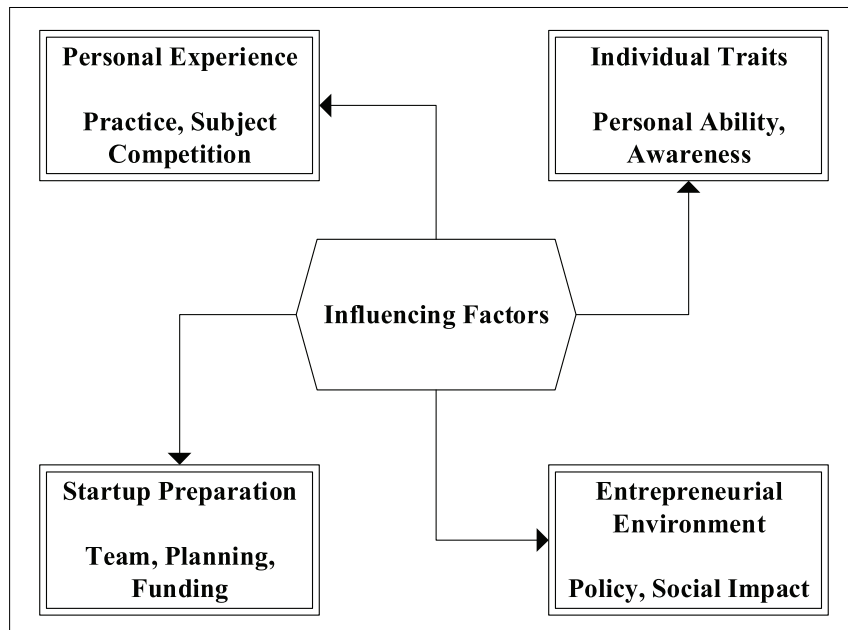

FIGURE 3 | The influencing factors of entrepreneurial choice.

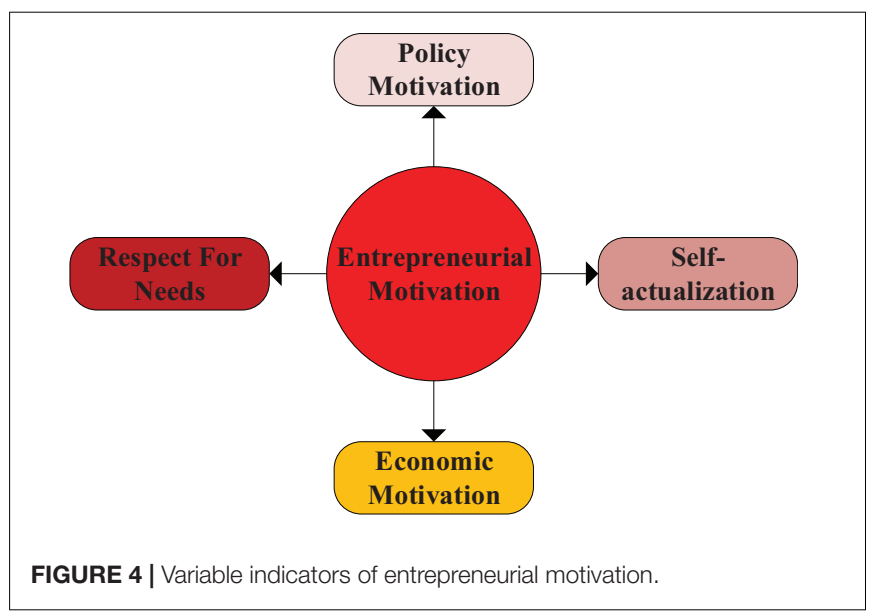

that the choice of entrepreneurial behavior of college students is restricted by many factors, and this epidemic has brought these influencing factors into play, which has a greater impact on entrepreneurs' motivation and environment. Therefore, this exploration aims to analyze the influencing factors in the epidemic environment and summarize the commonality and build the selection influencing factor model. Among the subjective factors, there are three aspects: entrepreneurial motivation, entrepreneurial ability and willingness to behave. Each of the three aspects includes several influencing factors:

(1) Entrepreneurial motivation: It is the motivation and purpose of entrepreneurs' entrepreneurial behavior and affects entrepreneurs' behavioral enthusiasm (Mahto and McDowell, 2018). Both internal motivation and external motivation can stimulate, maintain and adjust the entrepreneurial level. They are major influencing factors of entrepreneurs' behavior, including policy motivation, economic motivation, respect for needs and self-actualization. Figure 4 shows the structure.

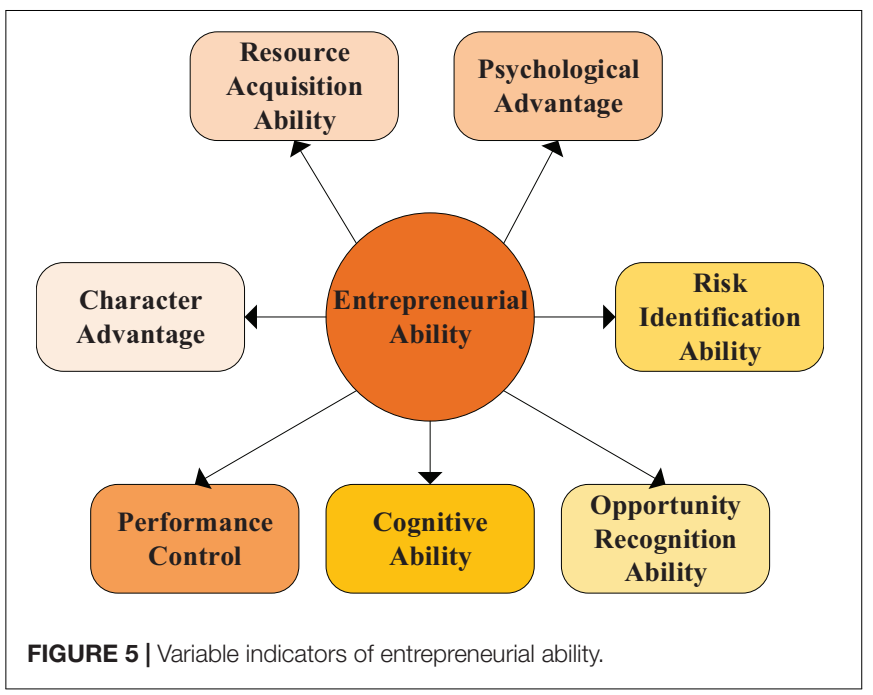

(2) Entrepreneurial ability: it is reflected in entrepreneurs' learning, cognition, innovation and practice, which is a necessary quality for an enterprise to succeed (Sun et al., 2020). Other comprehensive qualities can bring advantages in entrepreneurship. Combining entrepreneurial quality and entrepreneurial ability, this exploration aims to analyze the influencing factors of students' entrepreneurial behavior choice according to the impact of the epidemic on entrepreneurs themselves and the attitude of entrepreneurs toward the epidemic, and analyze entrepreneurial ability from the aspects of resource acquisition ability, risk identification ability, character advantage, psychological advantage, opportunity recognition ability and performance control. Figure $\mathbf{5}$ shows the structure and content.

(3) Willingness to behave: willingness is a kind of emotional state of people essentially, which is a designated goal or measure that people face when they want to get something (Tentama, 2018). Behavior is the action made by people according to their psychological instructions, which can express people's attitudes. In the process of entrepreneurship, college students can analyze the impact of the environment in terms of entrepreneurial goals, decisions, and actions. The research indicators of behavior intention here are the degree of willingness to behave.

(4) Objective factors mainly refer to the entrepreneurial environment. The impact of the external environment on entrepreneurship includes public opinion and policy support, including the economic environment (Boudreaux et al., 2019), social environment, entrepreneurship education (Ndofirepi, 2020), policy support and impact of the epidemic (Lei et al., 2020). Figure 6 shows its structure.

Result hypothesis: based on the above factors affecting the choice of entrepreneurial behavior and the cognition of relevant research results, the hypothesis of research results is made.

H1: entrepreneurial motivation has a positive impact on entrepreneurial behavior choice: good entrepreneurial 


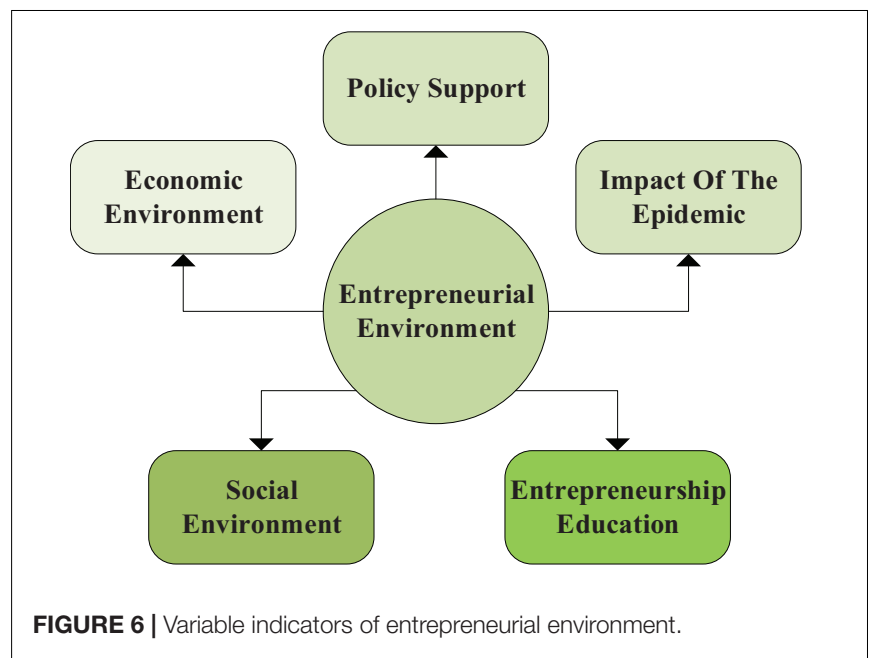

motivation can stimulate entrepreneurs' enthusiasm and potential, which is conducive to achieving entrepreneurs' goal of the behavior choice.

$\mathrm{H} 2$ : entrepreneurial ability has a positive impact on the choice of entrepreneurial behavior: The strength of entrepreneurial ability can directly affect the initiative and rationality of entrepreneurial behavior. College students with entrepreneurial ability can strengthen their selfconfidence, and entrepreneurs with strong ability can make more excellent behavior choices in a complex environment in the case of an epidemic.

H3: willingness to behave has a positive impact on entrepreneurial behavior choice: the entrepreneurs' willingness to behave is the subjective performance of their upcoming or ongoing entrepreneurship. The strength of choice intention marks the influence degree of the behavior choice. Combined with the impact of the epidemic, it is considered that entrepreneurs with strong behavioral willingness will help them make entrepreneurial behavior choices.

H4: entrepreneurial environment has a positive impact on the choice of entrepreneurial behavior: the entrepreneurial environment is the impact of the external environment of college students' entrepreneurship, including economic, social and policy. The integration of college students' individuals and entrepreneurial environment is to produce entrepreneurial behavior.

H5: entrepreneurial motivation has a positive impact on entrepreneurial intention: some scholars believe that

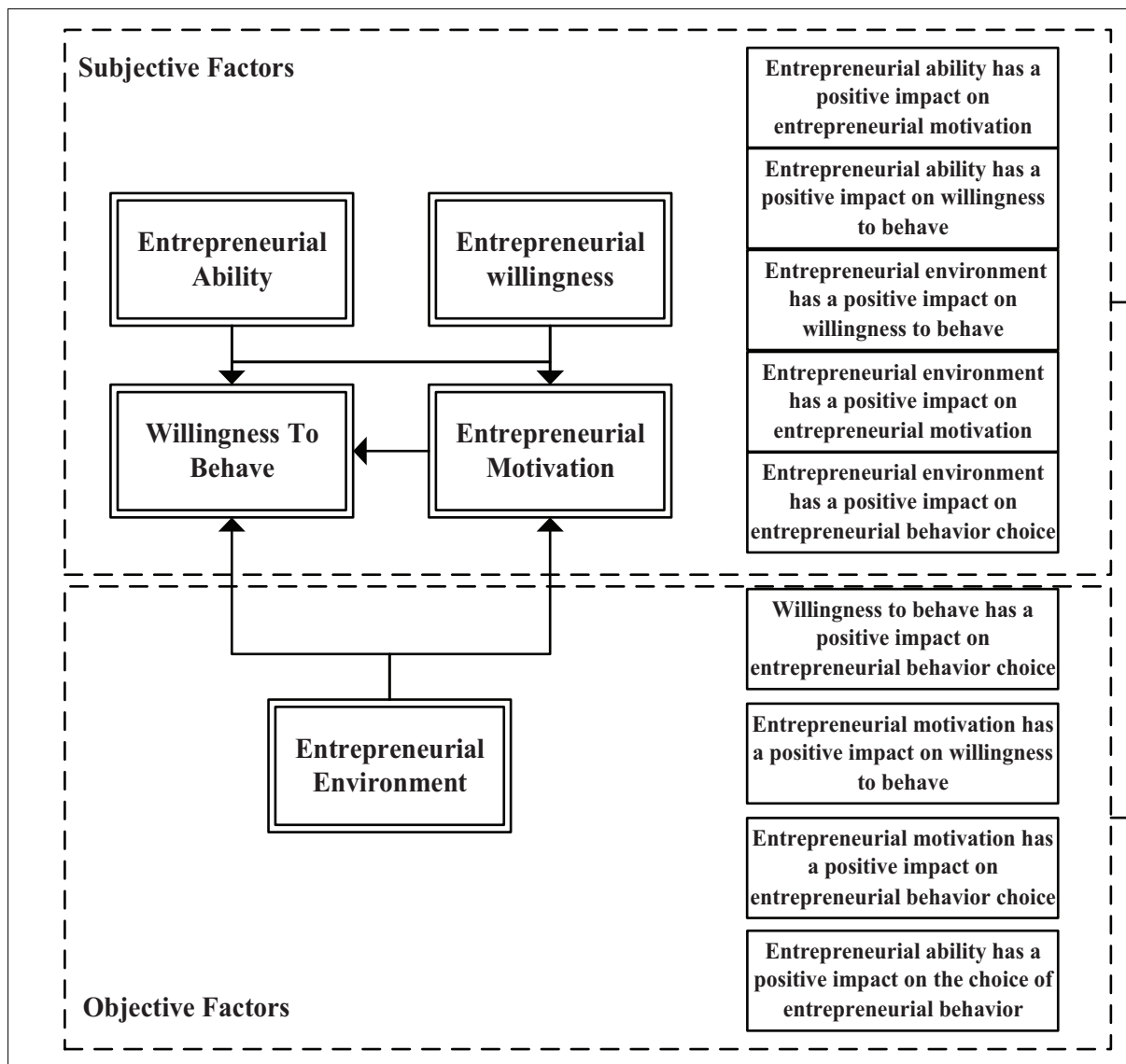

FIGURE 7 | The influencing factor model of the entrepreneurial behavior choice. 
entrepreneurial motivation has a significant impact on behavior intention and it is a factor of entrepreneurs' understanding of social rules.

H6: entrepreneurial ability has a positive impact on willingness to behave: the study of entrepreneurial motivation cannot omit the entrepreneur's own ability. Entrepreneurs will have different entrepreneurial motivations according to their own abilities. Therefore, the entrepreneurial ability will also have an impact on willingness to behave.

H7: entrepreneurial ability has a positive impact on entrepreneurial motivation: similar to $\mathrm{H} 6$, the strength of ability will change entrepreneurs' judgment of entrepreneurial motivation.

H8: entrepreneurial environment has a positive impact on willingness to behave: the quality of entrepreneurial environment will affect entrepreneurs' own understanding of entrepreneurship. A good environment will encourage college students' willingness, while a bad environment will inhibit college students' entrepreneurial intention.

H9: entrepreneurial environment has a positive impact on entrepreneurial motivation: social, family and school environments will stimulate entrepreneurs' psychology. The more favorable the environment is, the stronger the entrepreneurial motivation will be.

According to the summarized factors affecting the choice of entrepreneurial behavior, the relationship among variables is connected in series, and the influence model of entrepreneurial behavior choice is constructed on the premise of the epidemic situation, as shown in Figure 7.

\section{Questionnaire on Entrepreneurial Behavior of College Students}

The questionnaire can show the influencing factors of college students' entrepreneurial behavior choice in the epidemic era truly and accurately. First, the theories about college students' entrepreneurship on platforms such as college students' entrepreneurship competition or entrepreneurship work group are collected. Then, the first draft of the questionnaire is designed. Besides, the questionnaire is modified according to the actual situation. In the questionnaire, except for the personal information of the respondents, Likert grade 5 scoring scale (Park and Wu, 2019) is used for other questions. The questionnaire includes 5 variables of motivation, ability, willingness, environment and choice, and 26 corresponding observation variables as well. Table 1 shows the initial scale.

Reliability analysis of the questionnaire: the higher the reliability of the questionnaire is, the more accurate the actual situation is, and the more convincing the results of the questionnaire will be. Among the reliability analysis methods, the most widely used method is to use
Cronbach's a coefficient to calculate its reliability, and its equation is:

$$
\text { Alpha }=\left(\frac{k}{k-1}\right)\left(1-\frac{\sum_{i=1}^{k} S_{i}^{2}}{S_{x}^{2}}\right)
$$

In (1), $k$ represents the total number of questions, $S_{i}^{2}$ represents the variance of the score of the $\mathrm{i}$-th item, and $S_{x}^{2}$ represents the variance of the total number of items. It can be seen that the $\alpha$ coefficient can be used to measure the unity of attitudes and opinions.

The algorithm of SEM (Carden et al., 2019; Dwivedi et al., 2021) has the function of verification. It is an extension of the general linear model, which can make up for the shortcomings of traditional statistics and analyze multiple variables and results. The SEM generally requires that the sample size is greater than 100 , and the verification effect is the best if it is more than 200 . To meet $N / P>10$ and $N / t>5, N$ is the total sample capacity, $t$ is the number of free parameters, and $P$ is the total observed variable. Equation (2) displays the SEM equation:

$$
\eta=\beta \eta+\gamma \xi+\zeta
$$

$\eta$ represents the internal dependent variable, $\xi$ represents the external dependent variable, and $\zeta$ represents the residual term of the structural equation. Equations of the measurement model are:

$$
\begin{aligned}
& X=\wedge_{x} \xi+\delta \\
& Y=\wedge_{y} \eta+\epsilon
\end{aligned}
$$

Among them, $X$ and $Y$ represent the two observed variables for calculating the internal and external dependent variables $\eta$ and $\xi, \delta$ and $\epsilon$ are the errors of $X$ and $Y$ measurement, $\wedge_{x}$ is the load on the $X$ and $\xi$ variables, and $\wedge_{y}$ is the load on the $\eta$ variable.

Through the analysis of the various variables in Table 1, under the premise of ensuring the accuracy and reliability of the overall model, Figure 8 displays a schematic diagram of the model.

Overall, 300 questionnaires are distributed to classroom classes through online course software and offline colleges for 1 week's survey and feedback. A week later, 291 questionnaires are collected, and the incomplete and damaged parts are discarded. Overall, 260 valid questionnaires are collected, and the quantity meet the sample requirements. Table 2 shows the information statistics of the respondents.

After the basic information of 260 questionnaires is counted, the survey results of entrepreneurial behavior choice are analyzed. SPSS statistical software and Structural Equation Modeling (SEM) statistical data analysis method are used to analyze the results.

The reason for using SEM data analysis method is that the search performance of the search engine used in SEM analysis method is stronger than that of the Partial Lease Square (PLS), and SEM can convert data into results with higher conversion rate; moreover, the analysis structure of SEM analysis method is a three-dimensional and multi-level form, which can better show the driving force analysis of equipment. This three-dimensional analysis method is more in line with human thinking, which 
TABLE 1 | The initial scale of influencing factors.

\begin{tabular}{|c|c|c|c|}
\hline & Variable & Code & Questions \\
\hline \multirow[t]{8}{*}{ Basics } & Personal information (Bl1-8) & $\mathrm{Bl} 1$ & Gender \\
\hline & & $\mathrm{Bl} 2$ & Age \\
\hline & & $\mathrm{BI} 3$ & Educational background \\
\hline & & $\mathrm{B} 14$ & Professional type \\
\hline & & $\mathrm{Bl} 5$ & Number of entrepreneurial experiences \\
\hline & & $\mathrm{B} 16$ & The type of industry you are starting a business or about to start a business. \\
\hline & & $\mathrm{BI} 7$ & The model you are starting or about to start. \\
\hline & & $\mathrm{Bl} 8$ & Scale of entrepreneurship \\
\hline \multirow{16}{*}{$\begin{array}{l}\text { Subjective reasons } \\
\text { (motivation, ability, } \\
\text { willingness) }\end{array}$} & $\begin{array}{l}\text { Entrepreneurial motivation } \\
(\text { EM1-4) }\end{array}$ & EM1 & Recognized by the society \\
\hline & & EM2 & Accumulate wealth \\
\hline & & EM3 & Respond to government requirements \\
\hline & & EM4 & Realize personal wishes \\
\hline & Entrepreneurial ability (ERC1-9) & ERC1 & Stable financial and technical support \\
\hline & & ERC2 & Able to take risks \\
\hline & & ERC3 & Cheerful personality \\
\hline & & ERC4 & Positive attitude toward work and life \\
\hline & & ERC5 & Good business sense \\
\hline & & ERC6 & Clear self-awareness \\
\hline & & $\mathrm{ERC7}$ & Understand the requirements for entrepreneurship \\
\hline & & ERC8 & Strong management ability \\
\hline & & ERC9 & Hope to create performance \\
\hline & Willingness to behave (Bl1-3) & $\mathrm{Bl} 1$ & Change through behavioral choice \\
\hline & & $\mathrm{Bl} 2$ & The choice is important for entrepreneurship. \\
\hline & & $\mathrm{BI} 3$ & Changes must be made. \\
\hline \multirow[t]{5}{*}{$\begin{array}{l}\text { Scenario reason } \\
\text { (environment) }\end{array}$} & $\begin{array}{l}\text { Entrepreneurial environment } \\
\text { (EE1-5) }\end{array}$ & EE1 & The domestic situation is suitable for entrepreneurship. \\
\hline & & EE2 & Entrepreneurship is not affected by the epidemic. \\
\hline & & EE3 & With the support of relatives and friends \\
\hline & & EE4 & Received entrepreneurship education in school. \\
\hline & & EE5 & Entrepreneurship policy helps a lot. \\
\hline \multirow[t]{5}{*}{ Dependent variable (choice) } & Entrepreneurial choice (EC1-5) & EC1 & Have confidence in the choice. \\
\hline & & EC2 & The entrepreneurial process is relatively smooth. \\
\hline & & EC3 & The entrepreneurial intention is clear. \\
\hline & & EC4 & Able to make choices easily \\
\hline & & EC5 & The original intention of starting a business meets expectations. \\
\hline
\end{tabular}

cannot be achieved by traditional PLS analysis at present; next, SEM analysis model can analyze the data attributes that cannot be measured directly, such as abstract data such as user loyalty and satisfaction; finally, SEM analysis model can cause and effect the attributes of each data, so that different levels of data can be compared at the unified level.

SEM comprehensive fitting index is used to evaluate the support of observation data and conceptual model. The value range of the model is between 0 and 1 . The closer the value is to 0 , the better the observed data fit the model. According to the general standard, it needs to be less than 0.1 . The observed data can relatively fit with the model when the value is $<0.05$, the observed data can well fit with the model when the value is $<0.01$, the observed data and the model are quite well fitted when the value is $<0.08$. The value range of other fitting indexes is also between 0 and 1 . It is generally believed that the quality of a model should not be evaluated by one, but by multiple indexes.

\section{Harman Single Factor Test}

The basic hypothesis of Harman's single factor test is that if there is method variation, an unrotated factor will be precipitated when exploratory factor analysis is carried out on all items containing all research constructs, and this common factor explains most of the variation. At present, the more common method is to use confirmatory factor analysis and set the common factor number as 1 to accurately test the hypothesis that "a single factor explains all variations." Harman's single factor method is not the best but the most commonly used method. The characteristic of this method is to detect the effect of the result when the source of the common method deviation is not clear. If the result effect is significant, another method can be adopted for statistical 


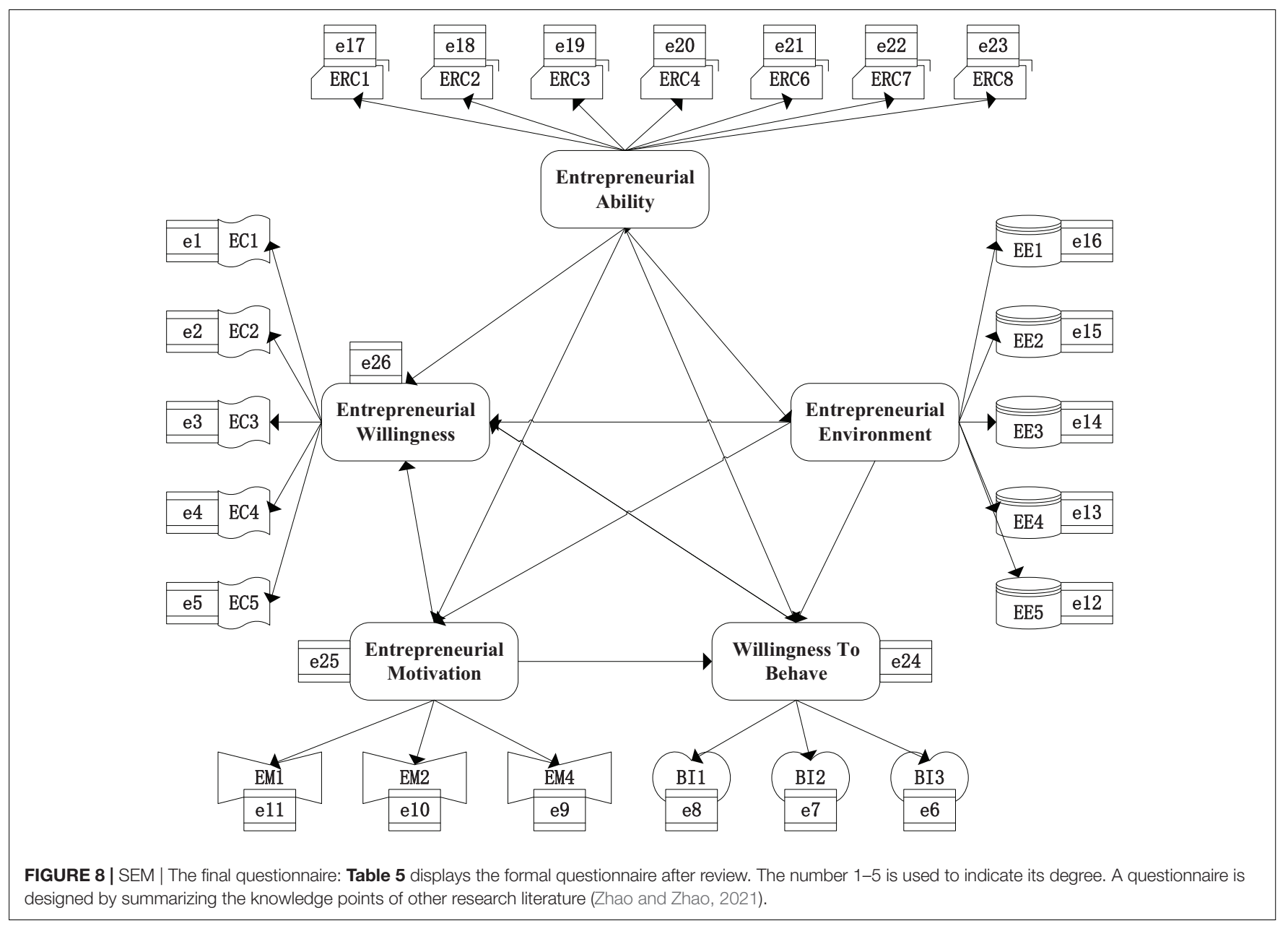

control. As the conclusion of this example, the chi square of the model is not significant. It can be considered that the effect of measurement error including common method deviation is not significant and will not have a serious impact on the research conclusion. If the test results are significant and explain a large amount of variation, does it mean that the common method

TABLE 2 | Statistics of objects.

\begin{tabular}{lcc}
\hline Category & Project & Quantity \\
\hline Gender & Male & 135 \\
\multirow{2}{*}{ Age } & Female & 125 \\
& $18-23$ & 186 \\
& $24-30$ & 58 \\
Academic degree & Over 30 & 16 \\
& Associate degree & 43 \\
& Bachelor degree & 168 \\
Major & Master's degree & 43 \\
& Doctor's degree & 6 \\
& Liberal arts & 62 \\
& Science and engineering & 165 \\
& Other & 33
\end{tabular}

deviation is significant? The answer is No. Perhaps the research variables themselves contain a meaningful common structure, which requires researchers to make scientific judgment.

\section{Adaptive Learning Method}

Adaptive learning is a means of educational science and technology. It provides independent help suitable for each student and has real-time interaction with students in reality. It requires various forms of learning resources, including text, image, sound, video and so on, in order to meet the needs of various learners. Adaptive learning style gives students strong autonomy in learning activities, and teachers only provide guidance. Adaptive learning reconstructs the knowledge acquisition mode. Students no longer rely too much on teachers' explanation and practice in traditional teaching, but carry out effective learning through interaction with the learning environment, so as to acquire and construct their own knowledge. It regards each learner as a VIP and provides the support of learning programs, computer technology, multimedia, artificial intelligence, communication and other high and new technologies only suitable for the learner. Inspiration: in the classroom, it is essential to learn to set a good learning driven situation according to students' psychology and 
TABLE 3 | Non-standardized coefficient.

\begin{tabular}{|c|c|c|c|c|}
\hline $\begin{array}{l}\text { Variable (arrow } \\
\text { indicates the influence } \\
\text { of the former on the } \\
\text { latter) }\end{array}$ & $\begin{array}{c}\text { Effect } \\
\text { value } \\
\text { (Estimate) }\end{array}$ & $\begin{array}{l}\text { Standard } \\
\text { error } \\
\text { (S.E.) }\end{array}$ & $\begin{array}{c}\text { Test } \\
\text { statistics } \\
\text { (C.R.) }\end{array}$ & $\begin{array}{c}\text { Significance } \\
\text { (P) }\end{array}$ \\
\hline Environment $\rightarrow$ motivation & 0.508 & 0.79 & 5.295 & \\
\hline Ability $\rightarrow$ motivation & 0.408 & 0.84 & 3.726 & \\
\hline Ability $\rightarrow$ willingness & 0.401 & 0.81 & 3.715 & \\
\hline Motivation $\rightarrow$ willingness & 0.248 & 0.82 & 1.948 & 0.003 \\
\hline Environment $\rightarrow$ willingness & 0.374 & 0.79 & 3.393 & \\
\hline Willingness $\rightarrow$ choice & 0.186 & 0.43 & 2.935 & \\
\hline Motivation $\rightarrow$ choice & 0.142 & 0.44 & 1.983 & 0.003 \\
\hline Environment $\rightarrow$ choice & 0.233 & 0.44 & 3.813 & \\
\hline Ability $\rightarrow$ choice & 0.172 & 0.45 & 2.785 & \\
\hline Choice $\rightarrow$ EC1 & 1.000 & & & \\
\hline Choice $\rightarrow$ EC2 & 1.456 & 0.138 & 10.007 & \\
\hline Choice $\rightarrow$ EC3 & 1.721 & 0.149 & 10.300 & \\
\hline Choice $\rightarrow$ EC4 & 1.721 & 0.142 & 10.871 & \\
\hline Choice $\rightarrow$ EC5 & 1.702 & 0.148 & 10.317 & \\
\hline Willingness $\rightarrow$ BI3 & 1.000 & & & \\
\hline Willingness $\rightarrow$ Bl2 & 1.045 & 0.058 & 15.812 & \\
\hline Willingness $\rightarrow$ Bl1 & 1.075 & 0.059 & 16.167 & \\
\hline Motivation $\rightarrow$ EM4 & 1.000 & & & \\
\hline Motivation $\rightarrow$ EM2 & 0.879 & 0.070 & 11.045 & \\
\hline Motivation $\rightarrow$ EM1 & 1.035 & 0.072 & 12.736 & \\
\hline Environment $\rightarrow$ EE5 & 1.000 & & & \\
\hline Environment $\rightarrow$ EE4 & 1.265 & 0.078 & 14.519 & \\
\hline Environment $\rightarrow$ EE3 & 1.105 & 0.080 & 12.214 & \\
\hline Environment $\rightarrow$ EE2 & 1.188 & 0.076 & 13.967 & \\
\hline Environment $\rightarrow$ EE1 & 1.085 & 0.079 & 12.175 & \\
\hline Ability $\rightarrow$ ERC1 & 1.000 & & & \\
\hline Ability $\rightarrow$ ERC2 & 0.953 & 0.075 & 11.142 & \\
\hline Ability $\rightarrow$ ERC3 & 0.877 & 0.064 & 12.037 & \\
\hline Ability $\rightarrow$ ERC4 & 1.008 & 0.066 & 13.441 & \\
\hline Ability $\rightarrow$ ERC6 & 1.016 & 0.079 & 11.249 & \\
\hline Ability $\rightarrow$ ERC7 & 0.829 & 0.068 & 10.568 & \\
\hline
\end{tabular}

future core literacy training, mobilize learning curiosity, create cognitive conflict, be student-oriented, construct their cognitive framework, guide and inspire their thinking.

Adaptive learning generally has three steps. First, it is necessary to establish an appropriate knowledge map according to the learned knowledge, and label and structure each knowledge point systematically; the second step is to make realistic mapping for the learning users; the third is to calculate the most suitable learning path for specific users through specific algorithms.

Entrepreneurial adaptive learning is a learning method that can significantly improve learning performance. The influencing factors of adaptive learning are different when learning is difficult. Among them, plan setting and reflection and error correction are important ways, which play different roles in the learning of entrepreneurial knowledge. Metacognitive level plays a regulatory and promoting role between entrepreneurial learning tasks and learning when starting a business.

Entrepreneurial learning is independently produced by learning objects under the change of environment. Entrepreneurs

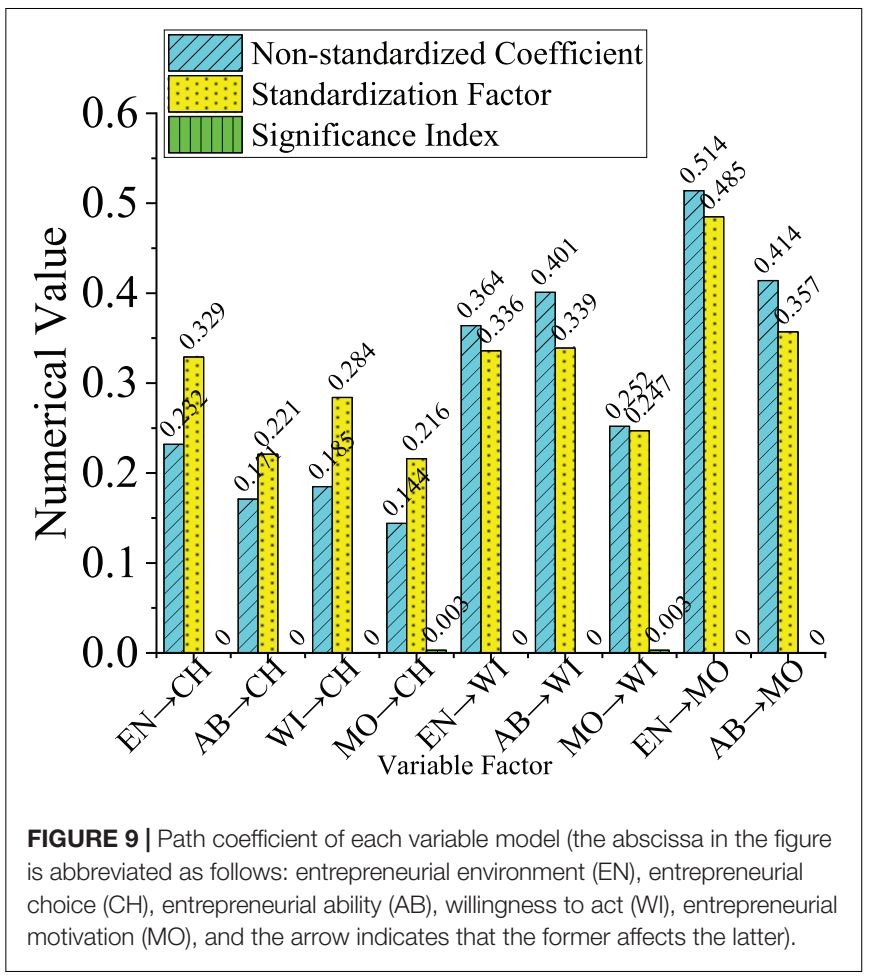

plan, implement and evaluate their actions, compare the interests they pursue with the feasibility of the problems they need to solve, and finally adjust the learning path. Entrepreneurial learning is very necessary, especially in the trial and error stage. With the progress of the entrepreneurial process, the entrepreneurial environment is constantly changing. Therefore, in this case, entrepreneurs need to have certain experience advantages in solving problems. Adaptive learning plays a very basic role in the learning process of entrepreneurship.

\section{RESULTS}

\section{Analysis of Standardized Coefficient of Questionnaire Results}

The SEM analysis method is used to make statistics and analysis on the result of the questionnaire on the data analysis software SPSS26.0. The non-standardized regression coefficient of each variable factor, the standard error of estimation parameters and the test statistics are calculated. Table 3 shows the non-standardized results. Then, the data are sorted out, and the standardization factor is shown in Figure 9. When the significance value is less than 0.001 , the numerical results are not displayed.

Figure 9 reveals that for the impact of entrepreneurial environment on entrepreneurial choice, the non-standardization coefficient is 0.232 , the standardization factor is 0.329 , and the significance index is 0 ; for the influence of entrepreneurial ability on entrepreneurial choice, the non-standardized coefficient is 0.171 , the standardized factor is 0.221 , and the significance index is 0 ; for the impact of behavior intention 
TABLE 4 | Hypothetical judgment.

\begin{tabular}{|c|c|c|c|}
\hline Hypothesis & $\begin{array}{c}\text { Standardization } \\
\text { factor }\end{array}$ & $\begin{array}{c}P \text {-value } \\
\text { judgment }\end{array}$ & $\begin{array}{c}\text { Is it } \\
\text { established? }\end{array}$ \\
\hline $\begin{array}{l}\text { H1: Entrepreneurial } \\
\text { motivation has a positive } \\
\text { impact on entrepreneurial } \\
\text { behavior choice. }\end{array}$ & 0.216 & $<0.001$ & Yes \\
\hline $\begin{array}{l}\mathrm{H} 2 \text { : Entrepreneurial ability } \\
\text { has a positive impact on } \\
\text { the choice of } \\
\text { entrepreneurial behavior. }\end{array}$ & 0.221 & $<0.001$ & Yes \\
\hline $\begin{array}{l}\text { H3: Willingness to behave } \\
\text { has a positive impact on } \\
\text { entrepreneurial behavior } \\
\text { choice. }\end{array}$ & 0.284 & $<0.001$ & Yes \\
\hline $\begin{array}{l}\text { H4: Entrepreneurial } \\
\text { environment has a positive } \\
\text { impact on entrepreneurial } \\
\text { behavior choice. }\end{array}$ & 0.329 & $<0.05$ & Yes \\
\hline $\begin{array}{l}\text { H5: Entrepreneurial } \\
\text { motivation has a positive } \\
\text { impact on entrepreneurial } \\
\text { intention. }\end{array}$ & 0.247 & $<0.05$ & Yes \\
\hline $\begin{array}{l}\text { H6: Entrepreneurial ability } \\
\text { has a positive impact on } \\
\text { willingness to behave. }\end{array}$ & 0.339 & $<0.001$ & Yes \\
\hline $\begin{array}{l}\text { H7: Entrepreneurial ability } \\
\text { has a positive impact on } \\
\text { entrepreneurial motivation. }\end{array}$ & 0.357 & $<0.001$ & Yes \\
\hline $\begin{array}{l}\text { H8: Entrepreneurial } \\
\text { environment has a positive } \\
\text { impact on willingness to } \\
\text { behave. }\end{array}$ & 0.336 & $<0.001$ & Yes \\
\hline $\begin{array}{l}\text { H9: Entrepreneurial } \\
\text { environment has a positive } \\
\text { impact on entrepreneurial } \\
\text { motivation }\end{array}$ & 0.485 & $<0.001$ & Yes \\
\hline
\end{tabular}

on entrepreneurial choice, the non-standardized coefficient is 0.185 , the standardized factor is 0.284 , and the significance index is 0 ; for the impact of entrepreneurial motivation on entrepreneurial choice, the non-standardized coefficient is 0.144 , the standardized factor is 0.215 , and the significance index is 0.003; for the impact of entrepreneurial environment on entrepreneurial intention, the non-standardized coefficient is 0.364 , the standardized factor is 0.336 , and the significance index is 0 ; for the influence of entrepreneurial ability on entrepreneurial intention, the non-standardized coefficient is 0.401 , the standardized factor is 0.339 , and the significance index is 0 ; for the impact of entrepreneurial motivation on entrepreneurial intention, the non-standardized coefficient is 0.252 , the standardized factor is 0.247 , and the significance index is 0.003; for the impact of entrepreneurial environment on entrepreneurial motivation, the non-standardized coefficient is 0.514 , the standardized factor is 0.485 , and the significance index is 0 ; finally, for the impact of entrepreneurial ability on entrepreneurial motivation, the non-standardized coefficient is 0.414 , the standardized factor is 0.357 , and the significance index is 0 . The analysis of Table 3 and Figure 9 reveal that the
TABLE 5 | Questionnaire on entrepreneurship behavior choice.

\begin{tabular}{ll} 
Basic & Gender \\
Information & A. male B. female \\
\hline & Age \\
A.18-23 B.24-30 C. over 30 \\
Educational background \\
A. associate degree B. bachelor degree C. master degree \\
D. doctoral degree \\
Major \\
A. liberal arts B. science and engineering C. others \\
Number of entrepreneurial experiences \\
A.1 B. 2 C. over 2 \\
The type of industry you are starting a business or about to \\
start a business. \\
A. agriculture B. architecture C. transportation D. computer \\
E. wholesale and retail F. restaurant G. internet technology \\
H. education I. entertainment J. others \\
The model you are starting or about to start. \\
A. independence B. imitation C. innovation \\
The scale of entrepreneurship \\
A. 1-10 people B.10-50 people C.50-200 people D. over \\
200 people \\
Degree of options: 1. very disagree 2. disagree 3. uncertain \\
4. relatively agree 5. very agree \\
Recognized by the society 1. 2. 3. 4. 5
\end{tabular}

motivation

Entrepreneurial ability

Accumulate wealth 1. 2. 3. 4. 5.

Realize personal wishes 1. 2. 3. 4. 5.

With the support of relatives and friends 1.2. 3. 4.5.

Able to take risks 1. 2. 3. 4. 5.

Cheerful personality 1. 2. 3. 4. 5.

Positive attitude toward work and life 1. 2. 3. 4. 5.

Good business sense 1. 2. 3. 4. 5.

Clear self-awareness 1. 2. 3. 4. 5.

Understand the requirements for entrepreneurship 1. 2. 3. 4. 5 .

Strong management ability 1. 2. 3. 4. 5.

Hope to create performance 1. 2. 3. 4. 5.

Willingness to behave

Change through behavioral choice 1. 2. 3. 4. 5.

The choice is important for entrepreneurship. 1. 2. 3. 4. 5.

Changes must be made. 1. 2. 3. 4. 5 .

Entrepreneurial environment

The domestic situation is suitable for entrepreneurship. 1. 2 . 3. 4.5.

Entrepreneurship is not affected by the epidemic. 1. 2. 3. 4. 5.

With the support of relatives and friends 1. 2. 3. 4. 5.

Received entrepreneurship education in school 1. 2. 3. 4. 5. Entrepreneurship policy helps a lot. 1. 2. 3. 4. 5.

Entrepreneurial Have confidence in choice 1. 2. 3. 4. 5.

choice

The entrepreneurial process is relatively smooth. 1. 2. 3. 4. 5.

The entrepreneurial intention is clear. 1.2. 3. 4. 5.

Able to make choices easily 1. 2. 3. 4. 5.

The original intention of starting a business meets expectations.

1. 2. 3. 4. 5. 
coefficients of $\mathrm{MO}, \mathrm{AB}, \mathrm{WI}$ and $\mathrm{EN}$ affecting entrepreneurial behavior choice are $0.216,0.221,0.284$, and 0.329 , respectively. In addition, $\mathrm{MO}, \mathrm{AB}$ and $\mathrm{EN}$ also affect behavior choice in the form of WI, and their coefficients are $(0.247 * 0.216)=0.070$, $(0.339 * 0.284)=0.096,(0.336 * 0.284)=0.095 . \mathrm{AB}$ and $\mathrm{EN}$ affect behavior choice through $\mathrm{MO}$, and the coefficient is $(0.357 * 0.216)=0.077,(0.485 * 0.216)=0.105$. Therefore, the influence coefficients of $\mathrm{MO}, \mathrm{AB}, \mathrm{WI}$ and $\mathrm{EN}$ on entrepreneurial behavior choice are $(0.216+0.07)=0.286,(0.221+0.096$ $+0.077)=0.394,0.284,(0.329+0.095+0.105)=0.529$, respectively. Therefore, the entrepreneurial ability and the entrepreneurial environment have a great impact on the choice of entrepreneurial behavior, followed by willingness to act and entrepreneurial motivation.

\section{Judgments of Hypothetical Result}

Comparing the above actual standardization factor and significance indicators with the hypothetical prediction to judge whether the hypothesis proposed is tenable. Table 4 shows the details.

Table 4 suggests that the hypotheses are all true, so it can be concluded that college students' entrepreneurial motivation, entrepreneur ability, willingness to behave and entrepreneurial environment will have a significant positive impact on college students' entrepreneurial choice behavior in the post epidemic era, among which the entrepreneurial environment has the most significant impact on entrepreneurial choice behavior. The judgment results of the above assumptions are as follows. The standardized effect value of $\mathrm{H} 1$ (entrepreneurial motivation has a positive impact on entrepreneurial behavior choice) is 0.216 , $P<0.001$, which is true; the standardized effect value of $\mathrm{H} 2$ (entrepreneurial ability has a positive impact on the choice of entrepreneurial behavior) is $0.221, P<0.001$, which is true; the standardized effect value of $\mathrm{H} 3$ (willingness to behave has a positive impact on entrepreneurial behavior choice) is 0.284 , $P<0.001$, which is true; the standardized effect value of $\mathrm{H} 4$ (entrepreneurial environment has a positive impact on the choice of entrepreneurial behavior) is $0.329, P<0.05$, which is true; the standardized effect value of $\mathrm{H} 5$ (entrepreneurial motivation has a positive impact on entrepreneurial intention) is $0.247, P<0.05$, which is true; the standardized effect value of $\mathrm{H} 6$ (entrepreneurial ability has a positive impact on willingness to behave) is 0.339 , $P<0.001$, which is true; the standardized effect value of $\mathrm{H} 7$ (entrepreneurial ability has a positive impact on entrepreneurial motivation) is $0.357, P<0.001$, which is true; the standardized effect value of $\mathrm{H} 8$ (entrepreneurial environment has a positive impact on willingness to behave) is $0.336, P<0.001$, which is true; the standardized effect value of $\mathrm{H} 9$ (entrepreneurial environment has a positive impact on entrepreneurial motivation) is 0.485 , $P<0.001$, which is true.

\section{DISCUSSION}

First, the influencing factors of college students' entrepreneurship under epidemic situation are analyzed by collecting relevant literature. Then, a questionnaire about entrepreneurial environment and entrepreneurial ability of college students who have started or will start a business is made. Finally, the reliability and validity of the survey results are tested by using data analysis software SPSS and analysis algorithm SEM to verify the correlation among variables. The research innovation lies in the analysis of the influencing factors of entrepreneurs' entrepreneurial behavior, and the coefficients of entrepreneurial motivation, entrepreneurial ability, behavioral willingness and entrepreneurial environment affecting the choice of entrepreneurial behavior are obtained; motivation, ability and environment also affect the coefficient of behavior choice in the form of behavior intention; entrepreneurial ability and environment affect the coefficient of behavior choice through motivation It is concluded that college students' entrepreneurial motivation, entrepreneur ability, behavior intention and entrepreneurial environment will exert a significant positive impact on college students' entrepreneurial choice behavior in the post epidemic era. Among them, the entrepreneurial environment has the most significant impact on entrepreneurial choice behavior. Ratten and Jones (2021) studied the relationship between entrepreneurship education and COVID-19 to help understand the future research and practice path. Several hypotheses changed due to COVID-19 and how entrepreneurship education is needed to help solve the entrepreneurship under pandemic are put forward. By considering entrepreneurship education as a whole process from the perspective of entrepreneurial stakeholders, how to carry out the response mechanism including recovery and change can be analyzed deeply. This enables people to regard the COVID-19 crisis as an opportunity to make more people focus more on the importance of entrepreneurship education to society (Ratten and Jones, 2021). Kawamorita et al. (2020) studied the relationship among college, industry, government, society and environment based on entrepreneurial intention. They believed that during the COVID-19 pandemic, they face multiple challenges, and the ecosystem needs their greater attention. The findings reveal the main challenges faced by entrepreneurial colleges and their related potential responses (Kawamorita et al., 2020). The result of the two studies are compared with that of this exploration. It is found that the conclusion is similar, that is, COVID-19 has a certain impact on the entrepreneurial intention of college students. In particular, the impact of entrepreneurial motivation and entrepreneurial environment on entrepreneurial intention further proves the correctness of the research content of this exploration. The entrepreneurial environment has the greatest impact on the choice of entrepreneurial behavior. Therefore, to increase college students' entrepreneurial willingness and motivation and enhance their entrepreneurial self-confidence, the government, society, colleges and families should strengthen the active guidance of students' entrepreneurial choice, create a good entrepreneurial environment and cultivate their entrepreneurial ability, to better cope with the impact of the post epidemic era on the economic system. Since the investigation is conducted after the outbreak, the sample size is small, which is not enough to support the entrepreneurial phenomenon of the whole society. In the future research, the scope of sample cities and the number of subjects will be expanded; moreover, 
the comprehensiveness and rationality of the questionnaire need to be further improved, and the variables of various influencing factors need to be subdivided and expanded. For example, the entrepreneurial environment can be subdivided into government, society, school and family environment. It is hoped that there will be a more in-depth discussion.

\section{CONCLUSION}

Based on the epidemic era, this exploration aims to study the influencing factors of college students' behavior choices in the process of entrepreneurship. First, relevant theoretical concepts are found and learned, the variables that affect the choice of entrepreneurial behavior are summarized and sorted out, and the assumptions about the results are made. Then, a questionnaire on the entrepreneurial motivation, entrepreneurial ability, willingness to behave and entrepreneurial environment of college students who have started or will start a business is made. Besides, the model is established based on the structural equation. Through the test, the degree of interaction among various variables is obtained, and it is proved that these variable factors have a positive impact on the choice of entrepreneurial behavior. The results are consistent with the prediction, which proves the correctness of the hypothesis. According to the empirical results, the analysis shows that in the epidemic era, the economic system has been affected and the entrepreneurial environment has changed greatly. College students will consider more environmental factors when starting a business, such as economic conditions, social environment, school environment and family environment. The government, society, colleges and families should strengthen the active guidance of students' entrepreneurial choice, create a good entrepreneurial environment and cultivate entrepreneurial ability, so as to better deal with the impact of the post epidemic era on the economic system. The practical significance of the conclusion is to provide some entrepreneurial ideas

\section{REFERENCES}

Allmendinger, M. P., and Berger, E. S. C. (2020). Selecting corporate firms for collaborative innovation: entrepreneurial decision making in asymmetric partnerships. Int. J. Innovat. Manag. 24, 2050003. doi: 10.1142/ S1363919620500036

Boahemaah, L., Xin, L., Dobge, C. S. K., and Pomegbe, W. W. K. (2020). The impact of entrepreneurship education on the entrepreneurial intention of students in tertiary institutions. Int. J. Manag. Account. Econ. 7, 180-212.

Boudreaux, C. J., Nikolaev, B. N., and Klein, P. (2019). Socio-cognitive traits and entrepreneurship: the moderating role of economic institutions. J. Bus. Vent. 34, 178-196. doi: 10.1016/j.jbusvent.2018.08.003

Caliendo, M., Goethner, M., and Weißenberger, M. (2020). Entrepreneurial persistence beyond survival: measurement and determinants. J. Small Bus. Manag. 58, 617-647. doi: 10.1080/00472778.2019.1666532

Cao, Z., and Wang, L. (2020). What factors decide the willingness of higher vocational college students to run a company: an empirical study of the impact of willingness to start business. Int. J. Educ. Cult. Soc. 5:85. doi: 10.11648/j.ijecs. 20200505.11

Carden, S. W., Camper, T. R., and Holtzman, N. S. (2019). Cronbach's alpha under insufficient effort responding: an analytic approach. Stats 2, 1-14. doi: $10.3390 /$ stats 2010001 for college students who are going to start a business. Entrepreneurship needs appropriate entrepreneurial objectives and firm entrepreneurial motivation. Besides, it also needs to choose whether to start a business according to its own entrepreneurial environment. The research limitation is that the number of survey samples is small, which is not enough to support the entrepreneurial phenomenon of the whole society. In the future research, the scope of sample cities and the number of subjects will be expanded; besides, the comprehensiveness and rationality of the questionnaire need to be further improved, and the variables of various influencing factors need to be subdivided and expanded. For example, the entrepreneurial environment is subdivided into government, society, school and family environment. It is hoped that there will be a more indepth discussion.

\section{DATA AVAILABILITY STATEMENT}

The raw data supporting the conclusions of this article will be made available by the authors, without undue reservation.

\section{ETHICS STATEMENT}

The studies involving human participants were reviewed and approved by the Lingnan University Ethics Committee. The patients/participants provided their written informed consent to participate in this study. Written informed consent was obtained from the individual(s) for the publication of any potentially identifiable images or data included in this article.

\section{AUTHOR CONTRIBUTIONS}

The author confirms being the sole contributor of this work and has approved it for publication.

Dwivedi, Y. K., Ismagilova, E., Sarker, P., Jeyaraj, A., Jadil, Y., and Hughes, L. (2021). A meta-analytic structural equation model for understanding social commerce adoption. Inf. Syst. Front. 1, 1-17. doi: 10.1007/978-3-319-271743_1

Feng, Y. (2020). Correlation between learning effect and psychological environment in english teaching: an empirical analysis based on ternary interaction theory. Rev. Argent. Clín. Psicol. 29: 327.

Hutasuhut, S. (2018). The roles of entrepreneurship knowledge, self-efficacy, family, education, and gender on entrepreneurial intention. Din. Pend. 13, 90-105.

Kawamorita, H., Salamzadeh, A., Demiryurek, K., and Ghajarzadeh, M. (2020). Entrepreneurial universities in times of crisis: Case of COVID-19 pandemic. J. Entrepreneurship Bus. Econ. 8, 77-88.

Lei, J., Hock, O. Y., and Asif, M. K. (2020). The influence of entrepreneurship education on innovation capability among chinese undergraduate students in COVID-19 pandemic era: a framework of analysis. Solid State Technol. 63, 2279-2296.

Mahto, R. V., and McDowell, W. C. (2018). Entrepreneurial motivation: a non-entrepreneur's journey to become an entrepreneur. Int. Entrepreneurship Manag. J. 14, 513-526. doi: 10.1007/s11365-0180513-8 
Murnieks, C. Y., Klotz, A. C., and Shepherd, D. A. (2020). Entrepreneurial motivation: a review of the literature and an agenda for future research. J. Organ. Behav. 41, 115-143. doi: 10.1002/job.2374

Ndofirepi, T. M. (2020). Relationship between entrepreneurship education and entrepreneurial goal intentions: psychological traits as mediators. J. Innovat. Entrepreneurship 9, 1-20. doi: 10.1186/s13731-020-0115-x

Park, M., and Wu, A. D. (2019). Item response tree models to investigate acquiescence and extreme response styles in Likert-type rating scales. Educ. Psychol. Meas. 79, 911-930. doi: 10.1177/0013164419829855

Ratten, V., and Jones, P. (2021). Covid-19 and entrepreneurship education: implications for advancing research and practice. Int. J. Manag. Educ. 19:100432. doi: 10.1016/j.ijme.2020.100432

Schmidt, R., and Stenger, K. (2021). Behavioral planning: improving behavioral design with "roughly right" foresight. Strat. Design Res. J. 14, 138-148. doi: 10.4013/sdrj.2021.141.12

Song, D., and $\mathrm{Wu}, \mathrm{Y}$. (2019). Gratifications for social media use in entrepreneurship courses: learners' perspective. Front. Psychol. 10:1270. doi: 10.3389/fpsyg.2019.01270

Sun, J., Huang, Y., Su, D., and Yang, C. (2020). Data mining and analysis of parttime entrepreneurs from the perspective of entrepreneurial ability. Inf. Syst. e-Bus. Manag. 18, 455-484. doi: 10.1007/s10257-019-00425-8

Tentama, F. (2018). The relationship between entrepreneurial motivation and entrepreneurial intensity on psychology students. J. Educ. Sci. Technol. 4, 26-31.

Ting, K. C., Lin, H. H., Chien, J. H., Tseng, K. C., and Hsu, C. H. (2021). How can sports entrepreneurs achieve their corporate sustainable development goals under the COVID-19 epidemic. Environ. Sci. Pollut. Res. 1, 1-16. doi: 10.1007/ s11356-021-16915-7

Vodǎ, A. I., and Florea, N. (2019). Impact of personality traits and entrepreneurship education on entrepreneurial intentions of business and engineering students. Sustainability 11:1192. doi: 10.3390/su11041192

Wang, H., Wu, W., and Wu, Y. J. (2020). Internal and external networks, and incubatees' performance in dynamic environments: entrepreneurial learning's mediating effect. J. Technol. Transfer 46, 1707-1733.

Wang, X. X., Wang, C. H., and Chang, C. C. (2018). The impacts on both family and personal factors for youth entrepreneurship. J. Discr. Math. Sci. Cryptogr. 21, 1205-1209. doi: 10.1080/09720529.2018.1525128

Wang, Y., and Hu, T. (2021). Analysis of the dilemma and development of small and medium-sized enterprises (SMEs) under the COVID-19. Front. Econ. Manag. 2:176-184.
Wenfeng, F. A. N. (2020). The status quo and countermeasures of college students' innovation and entrepreneurship activities in the new period. Theor. Pract. Innovat. Enntrepreneurship 3:190.

$\mathrm{Wu}, \mathrm{Y} ., \mathrm{Wu}, \mathrm{T}$. , and $\mathrm{Wu}, \mathrm{Y}$. C. (2017). A decade of entrepreneurship education in the Asia Pacific for future directions in theory and practice. Manag. Decis. 55, 1333-1350. doi: 10.1108/md-05-20170518

Yong, Z., Renlian, L., and Saragih, M. Y. (2020). The current situation, hot spot, and frontier of the research on the employment pressure of college students in China (quantitative visualization analysis based on CNKI core literature library in 2002-2019). Britain Int. Linguistic. Arts Educ. J. 2, 738-746. doi: 10.33258/biolae.v2i3.328

Zhang, L. (2020). Psychoanalysis on the innovation and entrepreneurship education of college students. Rev. Argent. Clín. Psicol. 29: 747.

Zhao, J., and Zhao, X. (2021). A study on guidance and incentive measures for undergraduate entrepreneurship. Open Access Library J. 8, 1-9. doi: 10.4236/ oalib.1107422

Zheng, C., Wu, W., Wang, H., and Wu, Y. J. (2019). Effect of narcissism, psychopathy, and machiavellianism on entrepreneurial intentionthe mediating of entrepreneurial self-efficacy. Front. Psychol. 10:360. doi: 10.3389/fpsyg.2019.00360

Conflict of Interest: The author declares that the research was conducted in the absence of any commercial or financial relationships that could be construed as a potential conflict of interest.

Publisher's Note: All claims expressed in this article are solely those of the authors and do not necessarily represent those of their affiliated organizations, or those of the publisher, the editors and the reviewers. Any product that may be evaluated in this article, or claim that may be made by its manufacturer, is not guaranteed or endorsed by the publisher.

Copyright $\odot 2022$ Yang. This is an open-access article distributed under the terms of the Creative Commons Attribution License (CC BY). The use, distribution or reproduction in other forums is permitted, provided the original author(s) and the copyright owner(s) are credited and that the original publication in this journal is cited, in accordance with accepted academic practice. No use, distribution or reproduction is permitted which does not comply with these terms. 